\title{
Corrosion Behavior of Anodic Self-Ordered Porous Oxide Layers on Stainless Steel
}

\author{
Lucia Helena Prado, (i) Evangelia Anastasiou, and Sannakaisa Virtanen ${ }^{*, z_{(\mathbb{D}}}$ \\ Institute for Surface Science and Corrosion, Department of Materials Science and Engineering, University of Erlangen- \\ Nuremberg, Germany
}

\begin{abstract}
In the present study we performed anodization of stainless steel AISI $316 \mathrm{~L}$ varying the voltage, time and $\mathrm{H}_{2} \mathrm{O}$ concentration in the electrolyte obtaining self-ordered porous oxides. Open-circuit potential measurements, potentiodynamic polarization and electrochemical impedance spectroscopy were performed in $0.1 \mathrm{M} \mathrm{H}_{2} \mathrm{SO}_{4}, 0.1 \mathrm{M} \mathrm{NaCl}$ and $0.1 \mathrm{M} \mathrm{NaOH}$ electrolytes. The metallic substrate underneath the grown oxide was also characterized. The results indicate that the corrosion behavior of the metallic substrate is not impaired by the anodization treatments. However, "crevice-induced intergranular corrosion" between the oxide and the metallic substrate was revealed after electrochemical measurements in the acidic electrolyte.

(C) 2021 The Author(s). Published on behalf of The Electrochemical Society by IOP Publishing Limited. This is an open access article distributed under the terms of the Creative Commons Attribution 4.0 License (CC BY, http://creativecommons.org/licenses/ by/4.0/), which permits unrestricted reuse of the work in any medium, provided the original work is properly cited. [DOI: $10.1149 /$ 1945-7111/abe1de]
\end{abstract}

Manuscript submitted December 1, 2020; revised manuscript received January 29, 2021. Published February 9, 2021.

Supplementary material for this article is available online

Over the last decades, metal anodization for growing nanostructured oxide layers has attracted considerable interest, as it allows the growth of porous structured oxides presenting a wide range of morphologies. The most common examples are aluminum ${ }^{1}$ and titanium $^{2}$ that can achieve highly ordered porous or nanotubular oxide arrays. Nanostructures based on anodization have been developed not only on valve metals, ${ }^{3}$ as later it was shown that it was possible to obtain self-assembled anodic porous oxides also on $\mathrm{Fe}^{4}$ In the last few years, fabrication of porous oxide layers on stainless steel by means of electrochemical anodization has become very promising for nanoscale surface structuring.

The first nanostructures on stainless steel AISI 316L were demonstrated by Vignal et al., 5 who performed electropolishing using an organic electrolyte with perchloric acid to obtain a dimplelike structure on the substrate surface. It was proposed that these morphologies were created by convective cells in the viscous shell formed in the substrate surface during the electropolishing process. Other researchers ${ }^{5-8}$ used very similar electropolishing approaches to obtain similar porous structures using different stainless steels as substrate and performing anodization in organic electrolytes also with perchloric acid. Later, Zhang et al. ${ }^{9}$ developed a two-step process to grow a porous oxide on stainless steel, in which in the first step a porous dimple-like structure was obtained, followed by an anodization step to grow an oxide layer using the previously obtained structure as a template. Another method for growing a porous oxide was presented previously, ${ }^{10,11}$ in which a squared shaped wave potential was applied in an acidic electrolyte, leading to a dissolution/deposition process to grow a disordered porous oxide film on stainless steel AISI 304 and 316L respectively. Farrag et al. ${ }^{12}$ also obtained a porous oxide layer in a $316 \mathrm{~L}$ substrate using an acidic, fluorine containing organic based electrolyte.

Habazaki et al. ${ }^{13,14}$ were the first to present the possibility of growing a self-ordered porous oxide layer on the surface of stainless steel AISI 304 using an ethylene glycol with $\mathrm{NH}_{4} \mathrm{~F}$ and water electrolyte with a galvanostatic bias. Later, anodization of 304 stainless steel in glycerol electrolytes containing $\mathrm{HN}_{4} \mathrm{~F}$ and $\mathrm{H}_{2} \mathrm{O}$ was shown to grow a porous oxide. ${ }^{15}$ Wang et al. ${ }^{16}$ studied the influence of some parameters (such as potential and anodization time) on the morphology and the formation mechanism of porous oxide layers on stainless steel AISI 304 anodized in a water and $\mathrm{NH}_{4} \mathrm{~F}$ containing ethylene glycol electrolyte achieving thicker oxide layers. These

*Electrochemical Society Fellow.

${ }^{\mathrm{z}}$ E-mail: virtanen@ww.uni-erlangen.de electrolytes are also widely used for growing porous and nanotubelike oxides on different valve metals such as titanium.

The mechanism of anodic porous oxide formation in the case of stainless steel is very similar to that of titanium and other metals. ${ }^{3}$ The process starts when a voltage is applied and a compact oxide starts to grow on the surface. This compact oxide hinders ion migration and thus the current decreases exponentially. After a few seconds, fluorides in the electrolyte start attacking the compact oxide at random places and small pores start to appear on the surface. At this point the current starts to deviate from its exponential decay. The roughness that starts to appear on the surface creates a different field distribution at the tops and valleys of the irregularities, leading to onset of pore growth. The growth takes place with an equilibrium between oxide formation and dissolution, with the inward migration of anionic species like $\mathrm{O}^{2-}, \mathrm{OH}^{-}$and $\mathrm{F}^{-}$from the electrolyte to the substrate/oxide interface and outward migration of cationic species such as metal ions. ${ }^{13}$ The ions that are extracted from the metal, migrate from the substrate to the electrolyte forming soluble compounds that are dissolved by the water in the electrolyte. Also, there is a uniform oxide dissolution at the outer oxide/electrolyteinterface. In the end, an equilibrium is reached between the growth of the oxide and its dissolution, and as the current stays constant, the oxide grows with a porous morphology.

The corrosion resistance of stainless steel is due to a native chromium-rich oxide on its surface that protects it from dissolution in chemically aggressive aqueous environments. This protective layer has a complex structure of iron and chromium oxide/ hydroxides species, chromium oxide being the species mainly responsible for the material protection. Under specific conditions stainless steel can suffer from localized breakdown of passivity, such as pitting corrosion in halide-containing electrolytes, enhanced by presence of impurity inclusions (such as MnS) on the surface. ${ }^{17}$ The addition of alloying elements can increase the stability of the passive state, as is the case with molybdenum that enhances the resistance of stainless steel AISI 316L against breakdown of passivity in chloride containing electrolytes.

To the best of our knowledge, few researchers have addressed the corrosion behavior of anodic porous oxide layers grown on stainless steel. Jaime et al. ${ }^{18}$ studied the corrosion behavior of anodic films grown on stainless steel AISI 304L (using an ethylene glycol based electrolyte with water and $\mathrm{NH}_{4} \mathrm{~F}$ ) in $0.6 \mathrm{M} \mathrm{NaCl}$ finding that the anodized samples were more susceptible to corrosion than the bare material. However, these studies were done with anodized samples without a subsequent annealing step. The structures that are grown during such anodization treatments in organic solvent with the presence of water and fluorides are very rich in fluoride and carbon 
from the electrolyte, which makes them highly soluble-in fact they can be dissolved just by staying in contact with the atmosphere for a couple of hours. Because of this it is necessary to perform an annealing step to remove the fluorides that are then replaced by oxygen, forming a stable oxide. Lee et al. ${ }^{19}$ also performed anodization of stainless steel AISI 304 (with the same electrolyte components as in Ref. 18) with an annealing step after anodization and further coated the porous oxide first with a polytetrafluoroethylene coating and subsequently infused with Krytox oil for corrosion protection applications. In this case, potentiodynamic polarization showed that the anodized sample presents a much lower corrosion current than the electropolished substrate in a $1 \mathrm{M} \mathrm{HCl}$ electrolyte.

As the corrosion resistance of stainless steel is directly related to its passive film, it is fundamental to characterize the corrosion behavior of anodized surfaces. Furthermore, as the oxides are grown at very high bias and in aggressive electrolytes, it is important to determine if these anodization processes could have a detrimental effect on the corrosion susceptibility of the underlying substrate. To answer these questions, a set of electrolytes and anodization parameters were selected amongst those in the presented literature and screening experiments for optimized anodization and subsequent characterization of the surface morphology, chemical composition and corrosion behavior were carried out. These optimization of anodization parameters was carried out using a design of experiments (DOE) approach to assess two key morphological aspects: coverage of the surface and the pore distribution. A set of samples was selected for analysis of surface composition and corrosion experiments in different electrolytes, to assess, if anodization parameters have an effect in the corrosion behavior of the resulting oxidized surfaces. Using another set of samples, the effect of the anodization process on the substrate was studied. For these samples, the oxide was removed after anodization, leaving the substrate surface exposed for surface analysis and corrosion experiments.

\section{Experimental}

Stainless steel AISI $316 \mathrm{~L}$ cut in $1 \times 20 \times 20 \mathrm{~mm}$ squared shaped specimens were used as substrates. One side was ground with up to $1200 \mathrm{SiC}$ grinding paper and then polished with up to $1 \mathrm{um}$ diamond suspension. After polishing, the samples were cleaned in an ultrasonication bath with acetone and ethanol.

Anodization was performed using a two electrode cell. The sample was connected as the anode at the bottom of the cell in a horizontal position, a platinum electrode was used as the cathode, the distance between electrodes being $1 \mathrm{~cm}$. One side of the substrate was in contact with the solution through a circular O-ring sealed opening exposing an area of $1 \mathrm{~cm}$ diameter. The temperature of the sample surface was fixed at $20^{\circ} \mathrm{C}$ by a thermostat connected to the opposite side of the anodized area. The electrolyte consisted of ethylene glycol, $\mathrm{NH}_{4} \mathrm{~F}$ concentration was $0.1 \mathrm{M}, \mathrm{H}_{2} \mathrm{O}$ concentration was $0.1 \mathrm{M}, 0.15 \mathrm{M}$, or $0.2 \mathrm{M}$ and voltage was set to $50 \mathrm{~V}, 70 \mathrm{~V}$ or $90 \mathrm{~V}$. The anodizations were performed in a two-step procedure to obtain a more regular structure. The first anodization step was performed using the parameters selected for each experiment with a fixed duration of 20 min After anodization, the formed easily soluble oxide was removed by means of ultrasonication in deionized water. Subsequently, the second anodization step was performed with the duration corresponding to each experiment. Then the sample was rinsed with 20 vol.\% water in ethanol to remove remnants of the

Table I. Experiment factors of the DOE and their respective levels.

Levels

\begin{tabular}{lccc}
\cline { 2 - 4 } Factors & -1 & 0 & 1 \\
\hline Voltage (V) & 50 & 70 & 90 \\
Time (min) & 10 & 20 & 30 \\
$\mathrm{H}_{2} \mathrm{O}(\mathrm{M})$ & 0.1 & 0.15 & 0.2
\end{tabular}

electrolyte and finally annealed at $400{ }^{\circ} \mathrm{C}$ for one hour in air. For the samples used to characterize the behavior of the substrate beneath the anodic oxide layer, no annealing was used. Instead, the oxide layer after the second anodization step was removed by ultrasonication in distilled water.

Despite the interest in stainless steel anodization for obtaining nanostructured oxides, few researchers have presented different morphologies that can be achieved with different parameters. Thus, it is important to assess if there is a correlation between the presence of an anodic layer and corrosion behavior. The methodology of design of experiments (DOE) was used to have a first insights on which type of nanostructures can be obtained. This approach has been previously used to study oxide nanotube formation on aluminum ${ }^{20}$ and titanium. ${ }^{21,22}$ From this set of experiments, some samples were selected for surface analysis and studies of the corrosion behavior.

The DOE approach was chosen because it allows to investigate not only the main effect of each parameter but also its interaction with other parameters, i.e., it is possible to identify, if the effect of one factor is bound to the level of another factor with a minimum amount of required experiments. A factorial design was employed with water concentration, voltage and anodization time as factors, having three levels each (indicated as $+1,0$ and -1 in Table I). The combination of parameters for each experiment can be seen in Table II. Both surface coverage of the porous oxide and the pore distribution (see below) in the oxide were studied using the software ImageJ. ${ }^{23}$ To obtain the effect of the obtained variable responses and its interactions, the DOE analysis was performed using the software Rstudio. $^{24}$

For calculating the surface coverage, SEM images were used, thus the area covered with oxide was divided by the total area of the picture. For analyzing the distribution of the porous structure the nearest neighbor approach was used. ${ }^{25-28}$ In the first stage the position of the center of each pore was obtained creating a list of $\mathrm{x}$ and $\mathrm{y}$ coordinates, then the nearest neighbor distance was calculated for each of these locations ${ }^{29}$ which consequently were used for calculating the nearest neighbor statistic given by formula 1 .

$$
\mathrm{Rn}=\left(\left(\sum(\mathrm{d} 1 \ldots \mathrm{dn})\right) / \mathrm{n}\right) /(0.5 \times \sqrt{ }(\mathrm{a} / \mathrm{n}))
$$

where $\mathrm{a}$ is the studied area, $\mathrm{n}$ the number of pores and $\mathrm{dx}$ the distance between each pore and its nearest neighbor. It can be seen that the numerator represents the mean value of the actual distance measured for each pore to its nearest neighbor and the denominator corresponds to the distance theoretically predicted between different pores. Thus, if $\mathrm{Rn}$ is near to one, the pores in the images have a random distribution, if $\mathrm{Rn}$ is close to zero then the points are highly clustered and if it is near 2 the points have a regular distribution.

Surface morphology was characterized with scanning electron microscopy (SEM, Hitachi s-4800). Cross sectional samples were fabricated with ion milling using argon ions and investigated with SEM. Surface composition and depth profiles were measured with X-ray photoelectron spectroscopy (XPS, PHI 5600, US), and peak positions were calibrated with respect to the $\mathrm{C} 1 \mathrm{~s}$ peak at $284.5 \mathrm{eV}$. For depth profiles Ar gas was used for sputtering. Additional SEM characterization (see supplementary information Fig. S2 available online at stacks.iop.org/JES/168/021507/mmedia) was carried out by scanning electron microscopy (SEM, Tescan LYRA3) while composition analysis (SI, Fig. S3) was performed by energy dispersive X-ray (EDX, EDAX/TSL Genesis 4000).

Corrosion experiments were performed in $0.1 \mathrm{M} \mathrm{H}_{2} \mathrm{SO}_{4}, 0.1 \mathrm{M}$ $\mathrm{NaCl}$ and $0.1 \mathrm{M} \mathrm{NaOH}$ electrolytes. A three electrode configuration was used with the sample connected as the working electrode, a platinum electrode as a counter electrode, and an $\mathrm{Ag} / \mathrm{AgCl}(3 \mathrm{M})$ as a reference electrode. In the case of the experiments performed in the $0.1 \mathrm{M} \mathrm{NaOH}$ solution a leakless miniature $\mathrm{Ag} / \mathrm{AgCl}$ electrode (ET072-1, eDAQ Pty Ltd.) was used. Each experiment is presented regarding the corresponding reference electrode used for each experiment. The sample was 
Table II. Factors settings of the DOE and the responses obtained for surface covering by the oxide and pores distribution.

Factors

\begin{tabular}{lcc}
\cline { 2 - 3 } Experiment number & Voltage & Time \\
\hline 1 & -1 & -1 \\
2 & +1 & -1 \\
3 & -1 & +1 \\
4 & +1 & +1 \\
5 & -1 & -1 \\
6 & +1 & -1 \\
7 & -1 & +1 \\
8 & +1 & +1 \\
9 & 0 & 0 \\
10 & 0 & 0
\end{tabular}

in contact with the solution through a circular O-ring sealed opening exposing a circular area of $7 \mathrm{~mm}$ diameter. For each solution, open circuit potential measurement (OCP, Zahner Zennium Electrochemical Workstation) was performed for one hour. The obtained OCP values are presented in Fig. S4 in the Supplementary Information. As soon as the OCP measurement was concluded, potentiodynamic polarization was conducted at room temperature with a $1 \mathrm{mV} \mathrm{s}^{-1}$ scanning rate, from $-300 \mathrm{mV}$ vs the OCP until $1.6 \mathrm{~V}$ in the anodic direction. Electrochemical Impedance Spectroscopy (EIS) was measured at the corrosion potential (Ecorr) with an amplitude of $+/-10 \mathrm{mV}$ in a frequency range of $10 \mathrm{kHz}-10 \mathrm{mHz}$.

\section{Results and Discussion}

SEM images of the porous oxides obtained with the factorial design are shown in Fig. 1. The pictures with higher magnification were used to study the pore distribution while the lower magnification pictures were used for assessing the percentage of the surface covered by the porous oxide layer. Pictures with higher magnification from samples 3 and 4 show patches of a porous oxide layer while the space in between was not covered by a porous oxide (see Fig. S1 from the supplementary information). Pictures from Fig. 1 already illustrate that there is a considerable variability in the oxide morphology when varying anodization parameters. Table II presents the numeric values obtained from the images for oxide coverage and pore distribution.

Cross-sections of samples with higher oxide coverages are shown in Fig. 2 to have a clearer insight of the porous structure. It can be seen that the oxides present a barrier-like compact layer covered by the porous oxide layer. Between these two layers and the stainless steel substrate, a thermal $\mathrm{Fe}$ rich oxide layer was formed due to the high temperatures used during the annealing process. Figure 3 shows an XPS depth profile of a sample anodized at $90 \mathrm{~V}$ but only for $90 \mathrm{~s}$ to grow a thinner oxide that could be fully removed by the sputtering to reach the metallic substrate. This profile shows that in the first 35 min of sputtering, a composition profile very similar to samples prepared with the same parameters but with longer anodization duration (see Fig. 7) takes place. Towards the end of the profile the composition of the metallic substrate is reached. Between the oxide and the metallic substrate, an increase in the fluorine concentration takes place. This is due to the fact that fluorine can travel faster than oxygen through the oxide layer, generating a fluorine-enriched interlayer. ${ }^{3}$ Finally, in the region between this interlayer and the metallic substrate an $\mathrm{Fe}$ enriched zone formed during the annealing step can be distinguished. Composition analysis will be performed in more detail below. Some images in Fig. 2 also show a layer on top of the porous oxide that was built up due to the ion milling process, more information regarding this layer is presented in Figs. S2 and S3 in the Supplementary information.

Wang et al. suggested that the cross-linked connected morphology of the pores is related to the complete dissolution of $\mathrm{Ni}$ oxides formed in the oxide layer when the nanopores are growing, while $\mathrm{Fe}_{2} \mathrm{O}_{3}$ and $\mathrm{Cr}_{2} \mathrm{O}_{3}$ species are partially dissolved. ${ }^{16}$ Even though the anodization was performed with constant parameters, cross-sections from samples 7 and 8 (longer anodization times) present a layered structure. It was not possible to elucidate the cause of such layered structures, nevertheless we present here some examples from the literature where similar structures were obtained. A first possibility could be related to the fact that as the anodization is taking place, the electrolyte is changing its composition, due to the dissolved species, and by water uptake due to the highly hygroscopic nature of ethylene glycol. Albu et al. ${ }^{2}$ developed maps showing how the oxide nanostructure of $\mathrm{TiO}_{2}$ can change as a function of voltage and water content in the electrolyte. Changes in the electrolyte
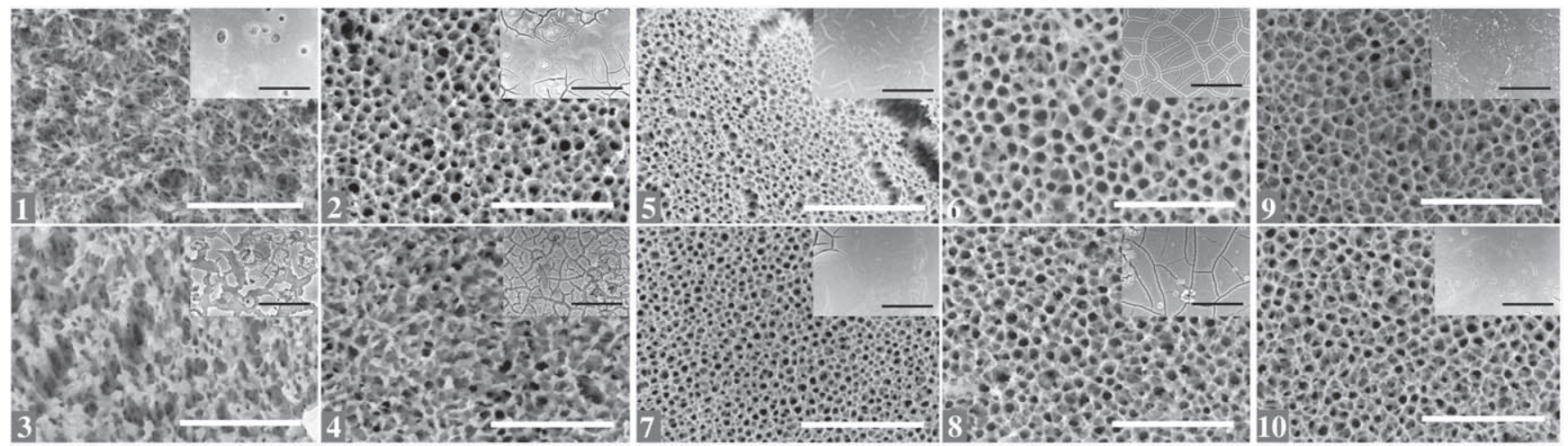

Figure 1. SEM images of the porous oxides obtained with the DOE approach. The inset pictures show the coverage of the surface by the oxide layer. The number in the left and bottom corner corresponds to the number experiment from Table I with the experiment parameters. The scale bar of the larger images is $1 \mu \mathrm{m}$ and the scale bar of the inset images corresponds to $50 \mu \mathrm{m}$. 

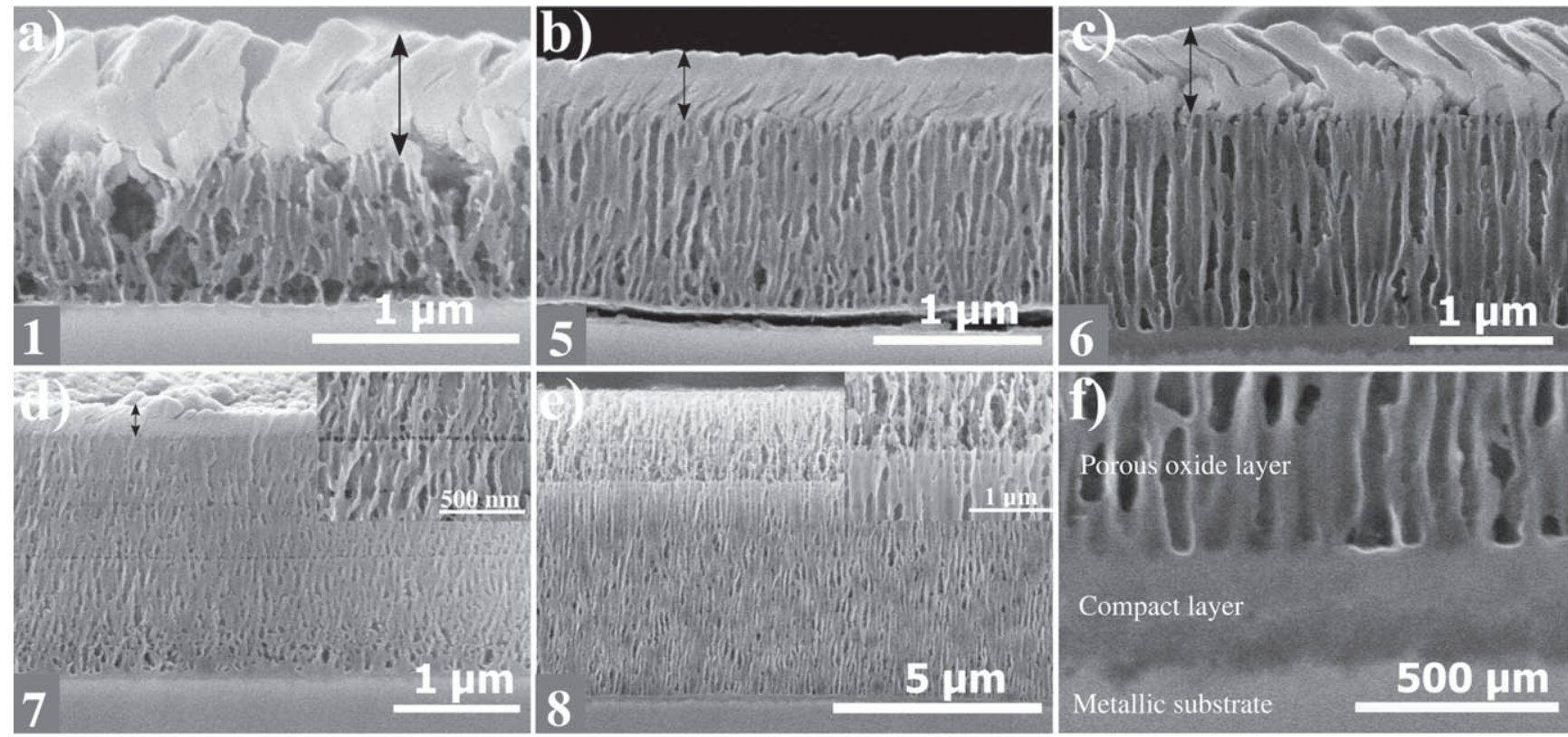

Figure 2. SEM images of cross-sections obtained by ion-milling of the porous oxide layers obtained with the DOE approach shown in Fig. 2. Figure (f) shows the metallic substrate, the compact barrier layer and the porous oxide layer with a higher magnification. The number in the left and bottom corner corresponds to the number experiment from Table I with the experiment parameters. The layer marked with an arrow in (a)-(d) is buildup material from the ion milling process.

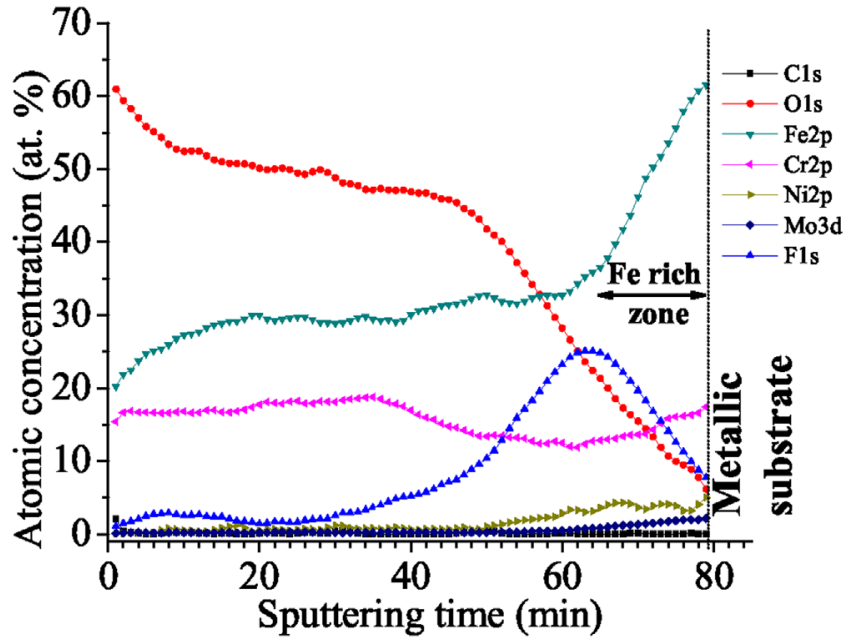

Figure 3. XPS sputter depth profiles of a sample anodized applying $90 \mathrm{~V}$ for $90 \mathrm{~s}$ in a $0.1 \mathrm{M} \mathrm{NH}_{4} \mathrm{~F}$ and $0.2 \mathrm{M} \mathrm{H}_{2} \mathrm{O}$ in ethylene glycol electrolyte. It can be seen that before reaching the metallic substrate an Fe enriched zone takes place.

composition are not sudden, but assuming that a similar scheme could be made for stainless steel anodization, the pore morphology could change upon reaching a threshold value in the composition, leading to the formation of an interface between different morphologies. Another example could be the study performed by Özkan et al., ${ }^{30}$ where Ti substrates were anodized in a fluoride containing di-methyl sulfoxide electrolyte using lactic acid as additive. In their work a multilayer porous oxide layer was obtained accompanied by periodic oscillations in the current. They concluded that the multilayer structure was influenced by the lactic acid concentration, applied voltage, established diffusion conditions and temperature. In our case we did not obtained such current oscilations, but the aspect of such layers are very similar to those shown in Fig. 2. Wang et al. ${ }^{16}$ also proposed the possibility of performing anodization with increasing voltage steps to maintain a continuous pore size, as the pores tend to become smaller due to the voltage decreasing through the oxide when it gets thicker. Between these potential steps, similar layered boundaries were found in the oxide structure. Another explanation could be the fact that the oxide is subjected to stresses that build up while it is growing. If certain stress would be reached where the oxide would slightly detach from the substrate, but not completely peel off, the anodization could continue with a slight interface between the detached layer and the one that continued growing below. We presented above different examples from the literature where similar layered structures were obtained, however in the case of stainless steel anodization further work would be necessary to elucidate the source of such patterns.

A repetition of the middle point experiments (9 and 10) shows that there is also some variability in the results obtained when using the same parameters. The size of the pores and the thickness of the oxide layers were not included in our analysis, as it is known that the pore size is directly related to the applied potential and the thickness to the duration of the anodization.

The bars in the Lenth plot (see Fig. 4) shows the effects and interactions obtained for each parameter. The length of each bar represents the effect while the positive or negative value is related to a positive or detrimental effect, respectively. For example, in Fig. 4 a can be seen that $\mathrm{H}_{2} \mathrm{O}$ concentration and its interaction with time have a positive effect leading to a higher covering of the surface by the porous oxide. However, the negative value of the time's effect shows that longer anodization time leads to a lower covering. The growth of the porous oxide takes place under a competition between oxide growth and its dissolution because of the water and fluorides present in the electrolyte. This dissolution is not only responsible for the formation of the pores, but also provokes a uniform dissolution at the interface between the surface of the oxide and the electrolyte. Besides, the solubility of the oxide after the anodization (and before the annealing step) is very high, so the structure is highly susceptible to any change in the electrolyte composition and also ambient humidity. With longer anodization times, the cracks on the structure will expose the oxide to be attacked from the sides, which might lead to the oxide patches that can be seen in the samples that were not fully covered. This can be added to the fact previously discussed, that the electrolyte is changing its composition and incorporating water, making this effect more aggravating with a longer anodization duration.

Table II presents the nearest neighbor statistic (Rn) obtained for all samples from the DOE arrangement. As can be seen, all the 


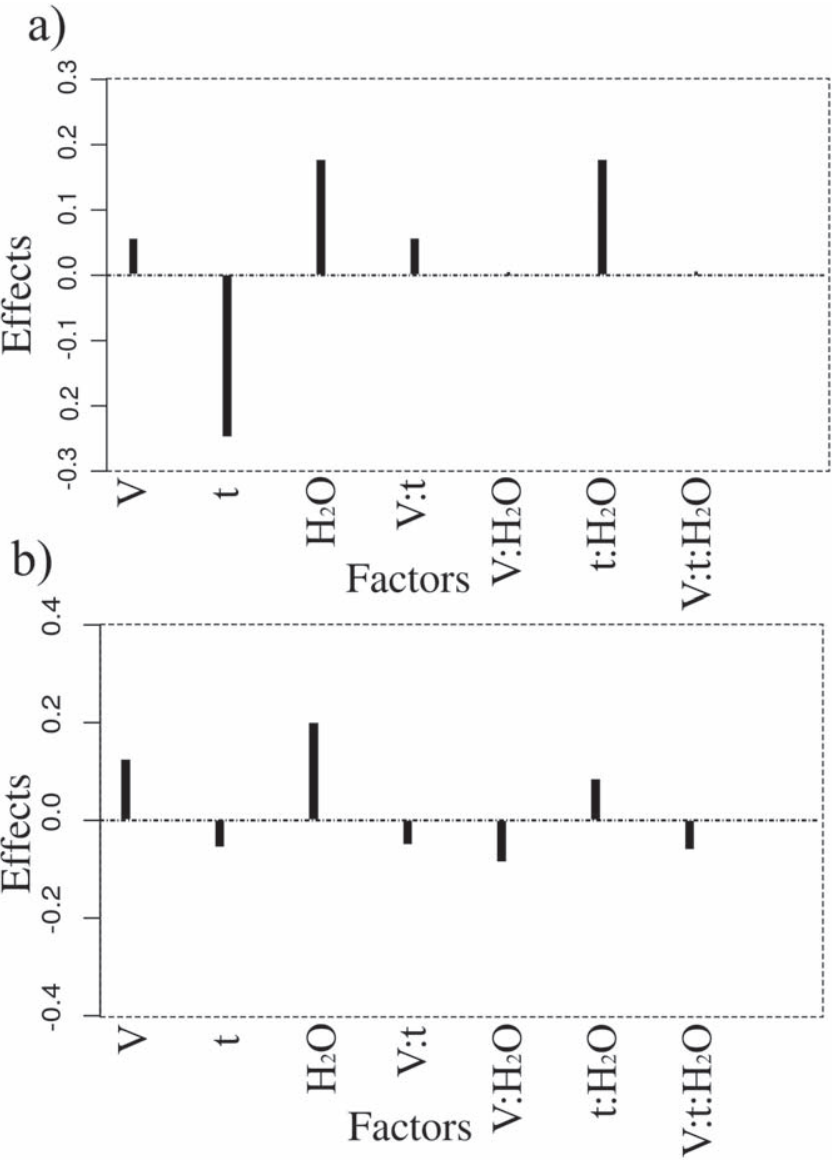

Figure 4. Lenth plots of the DOE analysis showing the effects of each parameter and its combination performed to investigate the effects and interaction of voltage, anodization time and $\mathrm{H}_{2} \mathrm{O}$ concentration in the electrolyte in (a) coverage of the porous oxide and (b) pores distribution in the oxide.

samples presented a value between 1 and 2, as in all pictures pores are distributed covering all the surfaces and do not present clustering. As expected from the SEM pictures, samples 1 and 3 present an irregular distribution with an $\mathrm{Rn}$ value nearer to 1 , while samples 7 and 8 (with a more ordered distribution) present a higher $\mathrm{Rn}$ value. The Lenth plot in Fig. $4 \mathrm{~b}$ revealed that the main effect on the pore distribution is due to water concentration.

It is interesting to remark that some applications are favored by presenting irregular structures, as is the case of superhydrophobic surfaces, where high roughness in the micro/nano scale, and even hierarchical roughness is desired. ${ }^{31,32}$ In this way, having a sampling of the different morphologies that can be obtained with stainless steel anodization is very interesting, as it can suit a wide range of applications. However, more work is necessary to further study in depth the correlation between anodization parameters and morphology of the oxides.

For analyzing the composition and corrosion behavior of the oxides, samples 5 and 6 from the factorial design were chosen (fabricated with $50 \mathrm{~V}$ and $90 \mathrm{~V}$, respectively, $0.2 \mathrm{M} \mathrm{H}_{2} \mathrm{O}$ concentration and a duration of $10 \mathrm{~min}$ ). In addition, a third sample was fabricated with $70 \mathrm{~V}$ (also $0.2 \mathrm{M} \mathrm{H}_{2} \mathrm{O}$ and a duration of $10 \mathrm{~min}$ ). These samples will be referred to as Oxide50V, Oxide70V and Oxide $90 \mathrm{~V}$, as the only difference in the fabrication process is the anodization voltage. As an important question to answer was, if the anodization process presented a detrimental effect on the alloy substrate composition beneath the grown oxide, two additional samples were produced following the same methodology than for samples Oxide50V and Oxide90V, but instead of a final annealing step, the oxide was removed with ultrasonication in water, revealing the metal substrate underneath it. This procedure was followed for samples 5 and 6 and will be referred to as Clean50V and Clean90V, accordingly. Finally, a bare polished stainless steel substrate was used as reference.

At high voltages chromium suffers for transpassive dissolution, forming $\mathrm{CrO}_{4}{ }^{2-}$ in the case of acidic solutions and $\mathrm{Cr}_{2} \mathrm{O}_{7}{ }^{2-}$ in neutral and alkaline solutions. ${ }^{33}$ It would be expected that at the high voltages used for the anodization, the formation of these soluble species could take place and that the composition of the oxide layer would be predominantly iron oxide species. However, according to Kure et al., ${ }^{13}$ the low amount of water in the electrolyte reduces dissolution of chromium species, allowing the oxide to grow with a high $\mathrm{Cr}$ concentration at high voltages, assisted by the intake of a high amount of fluorine which will be replaced by oxygen during the annealing process.

Figure 5 displays the XPS survey spectra and the high resolution spectra for each element, while Table III summarizes the surface composition calculated from the high resolution peaks. Due to their low surface concentration (see Table III), Ni and Mo high resolution spectra are not shown. In all anodized samples, carbon and fluorine are incorporated in the oxide layers from the electrolyte. There is also a higher carbon concentration on the surface due to adventitious carbon.

As can be seen in Fig. 5, clean samples still retain remnants of the oxide, providing information about changes in the layer composition when comparing them to the oxide layer after annealing. However, it is important to take into account that changes in the composition can occur by the cleaning step in water. The O1s spectra, clearly shows two peaks around $530.0 \mathrm{eV}$ and $531.5 \mathrm{eV}$ for the bare substrate that can be ascribed to metal oxides and metal hydroxides, respectively ${ }^{13}$-in line with typical findings for the native passive layer with a layered structure with these two components. ${ }^{34}$ After the anodization step, the cleaned samples show a higher binding energy for oxygen that can arise from a higher amount of hydroxides and adsorbed water on the surface. Finally, after annealing, the XPS O1s signal for both oxide samples shifts again to lower binding energies, indicating a composition of mainly metal oxides.

Fluorine is also present in the cleaned samples due to remnants of the oxide layers. The F1s signal of the cleaned samples present values mainly due to metal (II) and metal (III) fluorides $(684.4 \mathrm{eV}$ and $685.3 \mathrm{eV}$, respectively). ${ }^{15}$ On the other hand, after annealing, the F1s signal of the sample Oxide90V presents a lower binding energy (around $684.0 \mathrm{eV}$ ), possibly due to the formation of fluorine complexes with metal oxides and hydroxides. ${ }^{15}$ Also, presence of fluorine in the cleaned samples shifts the peaks of other elements towards higher binding energy values. ${ }^{13}$

According to the $\mathrm{Cr} 2 \mathrm{p}$ spectra, the native passive film on the bare substrate is mainly composed of $\mathrm{Cr}_{2} \mathrm{O}_{3}$ and in a lower amount of $\mathrm{Cr}(\mathrm{OH})_{3}\left(576.6 \mathrm{eV}\right.$ and $579.1 \mathrm{eV}$, respectively $\left.{ }^{13}\right)$. Again, oxide remnants on the cleaned samples lead to higher binding energies in the $\mathrm{Cr} 2 \mathrm{p}$ spectra, mainly because of $\mathrm{Cr}(\mathrm{OH})_{3}{ }^{11,35}$ but also at $579.0 \mathrm{eV}$ for $\mathrm{Cr}(\mathrm{VI})$ species ${ }^{5,35}$ and possibly $\mathrm{CrF}_{2} .{ }^{15}$ For the anodic layers after annealing, the chromium oxide peaks are enhanced and the presence of higher binding energy peaks is likely due to the formation of more $\mathrm{Cr}(\mathrm{VI})$ species in the annealing step. The fact that these higher energy signals are present in both annealed samples and also in the Clean90V sample spectra, could be an indication that $\mathrm{Cr}$ (VI) was formed both because of high voltage anodization and during the annealing process. This is important to take into account due to the toxic nature of $\mathrm{Cr}(\mathrm{VI})$ species. For the samples Clean50V and the bare substrate, a peak near $574.0 \mathrm{eV}$ can be ascribed to metallic $\mathrm{Cr},{ }^{36}$ as the oxide is thin enough to transmit photoelectrons from the metallic substrate.

$\mathrm{Fe} 2 \mathrm{p}$ spectra is more complex to analyze due to overlap of the spectral peaks and satellites. ${ }^{35}$ For example, the signal at $711.0 \mathrm{eV}$ can be related to $\mathrm{Fe}$ oxides, oxy-hydroxides, mixed $\mathrm{Fe}-\mathrm{Cr}$ oxides 
a)
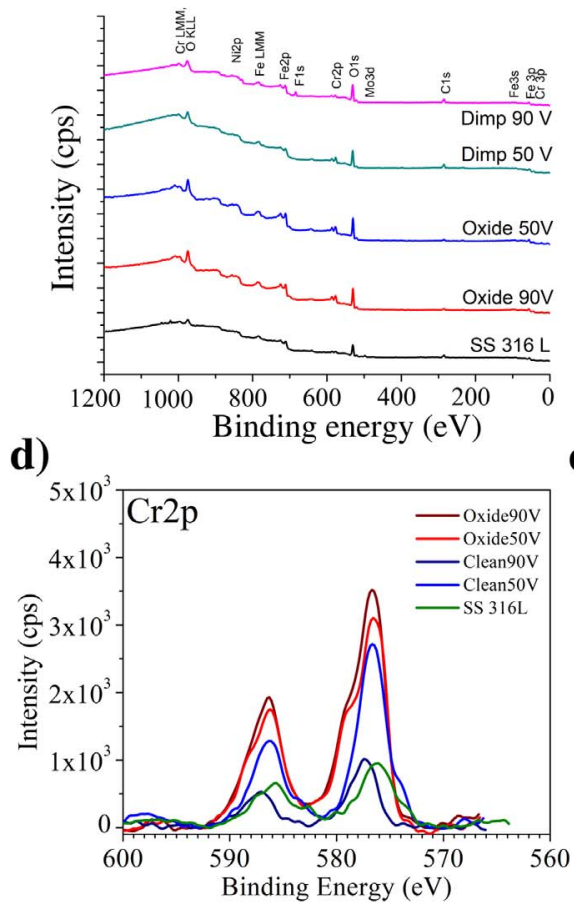

b)

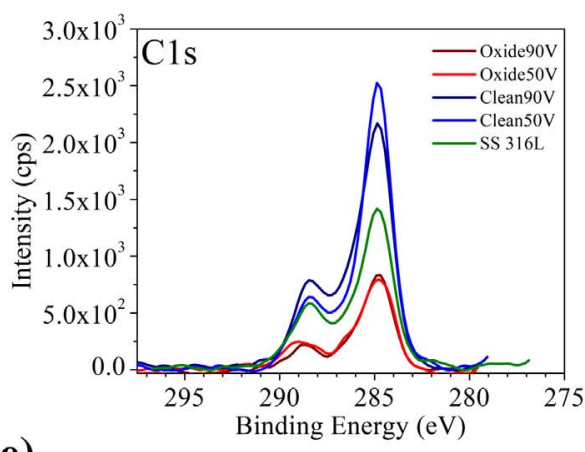

e)

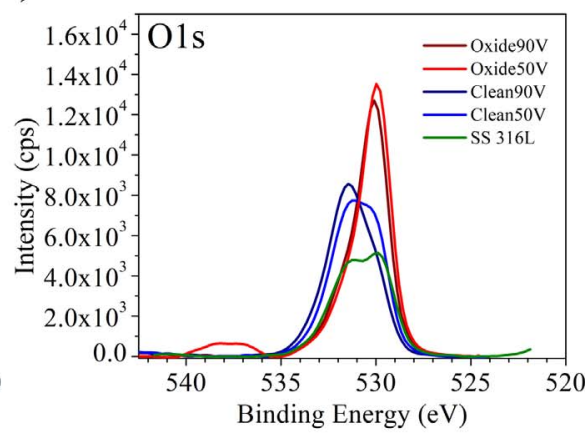

c)

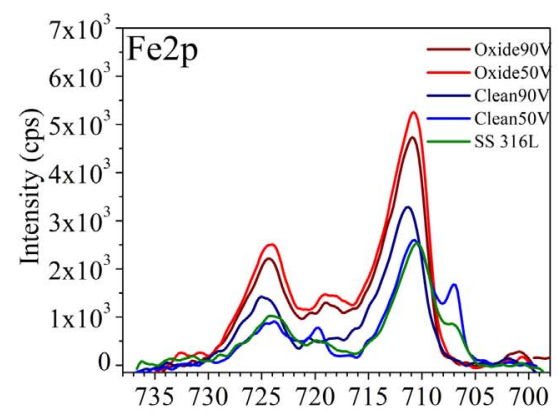

f)

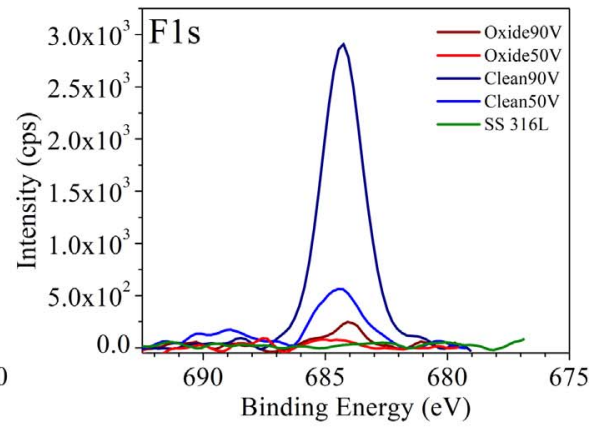

Figure 5. (a) XPS survey spectra and (b)-(h) high resolution spectra for oxides, cleaned samples and bare AISI 316L stainless steel.

Table III. XPS surface composition of porous oxides in at.\%, cleaned samples and bare AISI 316L stainless steel.

\begin{tabular}{lccccccc} 
& C1s & O1s & F1s & Cr2p & Fe2p & Ni2p \\
\hline Oxide90V & 11.77 & 59.16 & 0.67 & 12.20 & 14.53 & 1.26 \\
Oxide50V & 11.2 & 56.87 & 0.44 & 9.99 & 2.47 & 1.58 \\
Clean90V & 30.52 & 48.08 & 7.93 & 2.58 & 9.41 & 1.30 \\
Clean50V & 34.38 & 51.59 & 1.38 & 5.38 & 6.60 & 0.41 \\
SS AISI 316L & 28.63 & 50.35 & - & 10.13 & 9.42 & 0.19 \\
\end{tabular}

and $\mathrm{FeF}_{2}{ }^{15}$ At higher binding energies at ca. $713.0 \mathrm{eV}$, a hydroxidefluoride mixed compound could be present while the peak at $714.7 \mathrm{eV}$ could be related to $\mathrm{FeF}_{3}$ or a complex like $\left[\mathrm{FeF}_{6}\right]^{3-15}$ As well as in the Cr2p spectra, the bare substrate and the Clean $50 \mathrm{~V}$ samples show metallic Fe from the substrate underneath the oxide with binding energy around $706.6 \mathrm{eV} .{ }^{35}$

SEM top-view images of samples Clean50V and Clean90V are shown in Fig. 6. As can be seen, sample Clean90V presents some oxide remnants that were not removed by ultrasonication in water. On the other hand, the Clean50V sample had a shiny surface that appeared clean. The high resolution spectra of both samples present a high fluorine presence, and as expected, the Clean90V sample has the highest fluorine signal due to the oxide remnants. The presence of these oxide residues could be an indication of an inhomogeneous composition of the oxide that takes place mainly when using higher voltages. $\mathrm{O}$ and $\mathrm{F}$ signals from the XPS depth profile (see Fig. 7) of the Clean90V sample supports the presence of an oxide on the surface. However, apart from the presence of $\mathrm{F}$, its depth profile is very similar to that of the bare stainless steel sample.

For the samples Oxide90V and Oxide50V, the depth profiles show a very similar composition. Sputtering was performed until a sputter time of $100 \mathrm{~min}$, and as can be seen the stainless steel substrate was not reached. The $\mathrm{O}$ concentration is higher at the surface, and then diminishes until reaching a uniform value, while the concentration of metal ions decreases towards the surface. The main difference between the two samples is the uniform concentration of fluorine species in the Oxide $90 \mathrm{~V}$. The depth profiles of the oxide layers show a chromium concentration that is very similar to that of the substrate while the iron concentration is lower than in the substrate, indicating an increase in the chromium to iron ratio in the oxide layers.

It has been reported that during passivation of stainless steel there is an enrichment of nickel in the metal matrix beneath the oxide layer, as dominantly chromium and iron are oxidized to form the passive layer. ${ }^{37}$ On the other hand, it was reported by ${ }^{12}$ that in the case of stainless steel anodization in organic electrolytes at high voltages, all components are uniformly dissolved. In our case, XPS depth profile did not give any indication of selective dealloying. Besides, as the potentials used for the anodization are high, there may be less differences in the oxidation of the different alloying elements.

Potentiodynamic polarization curves in Fig. 8 show passive behavior in all electrolytes and for all samples (bare stainless steel, samples with anodic layers and samples with oxide layers removed after anodization). In $0.1 \mathrm{M} \mathrm{NaCl}$, the passive region is limited by onset of pitting corrosion. The passive current densities and the pitting potential are very similar for the bare stainless steel and the anodized samples after removal of the oxides layer. This indicates that anodization does not impair the pitting resistance of the substrate. Also, the current densities are much higher for the samples with the anodic oxide layers and a distinct pitting potential cannot be detected. The OCP measurements for the oxide layers (Fig. S4 in the Supplementary information) also show cathodic oscillations 

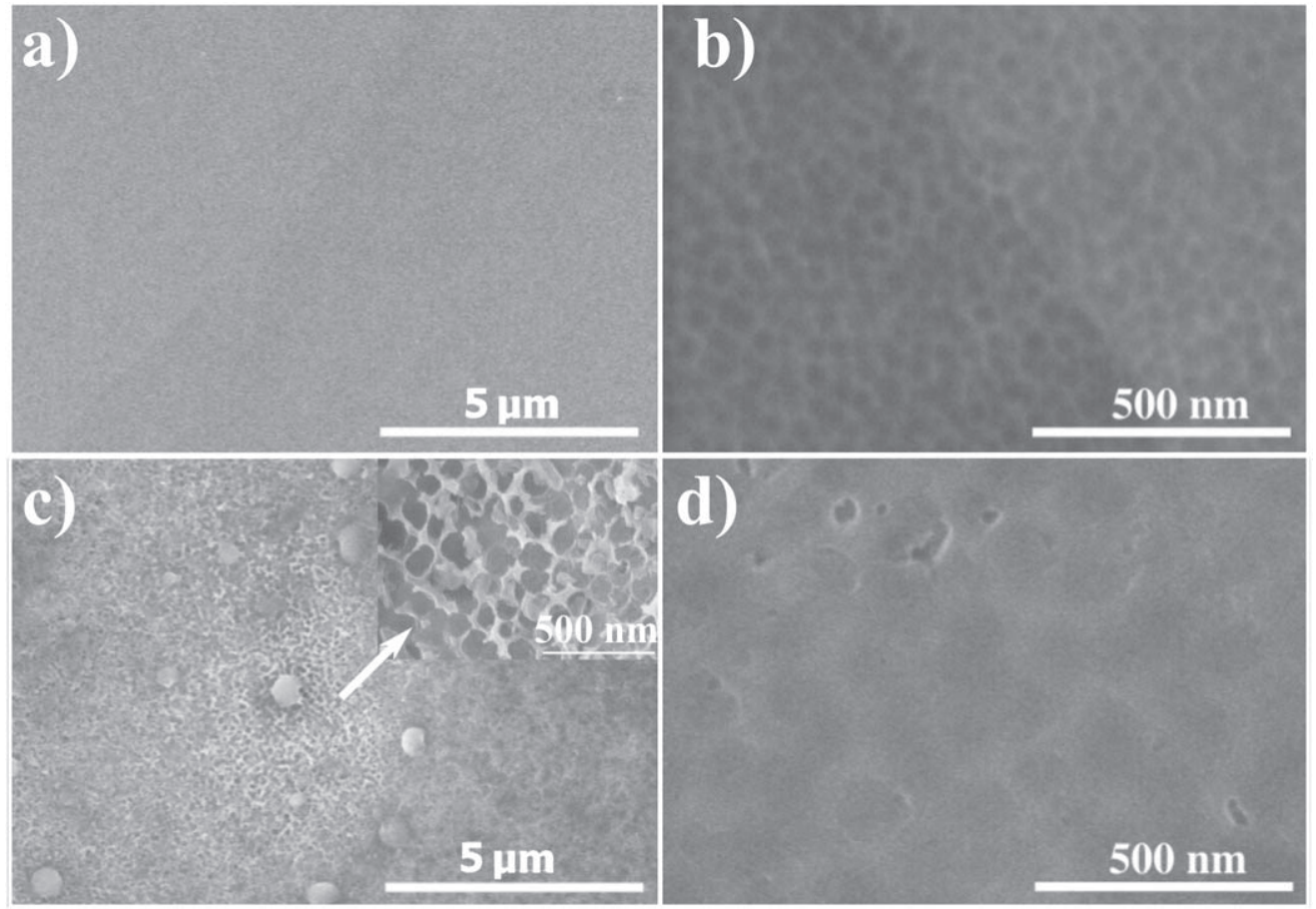

Figure 6. SEM images of (a) Clean50V (b) Clean50V with higher magnification, (c) Clean90V and (d) Clean90V with higher magnification.

a)

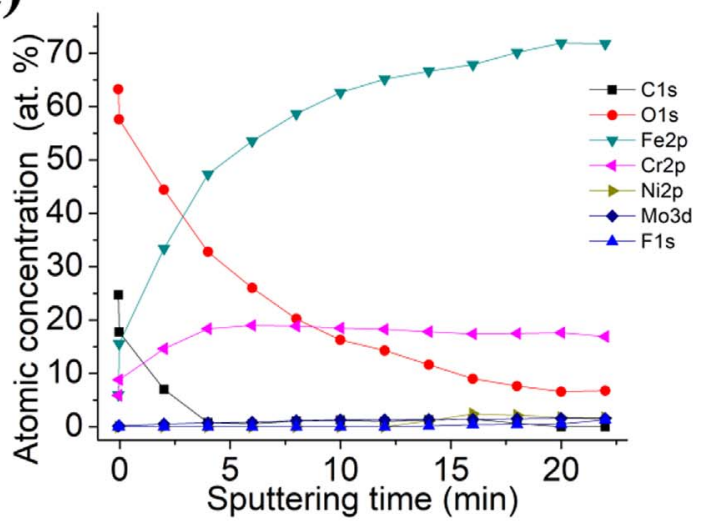

c)

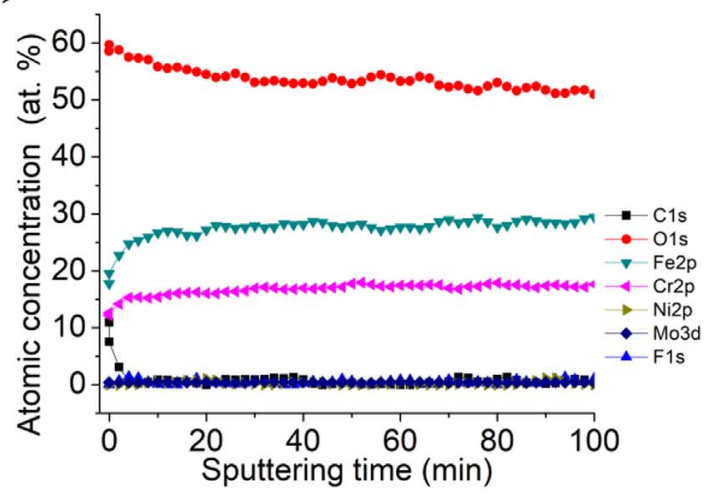

b)

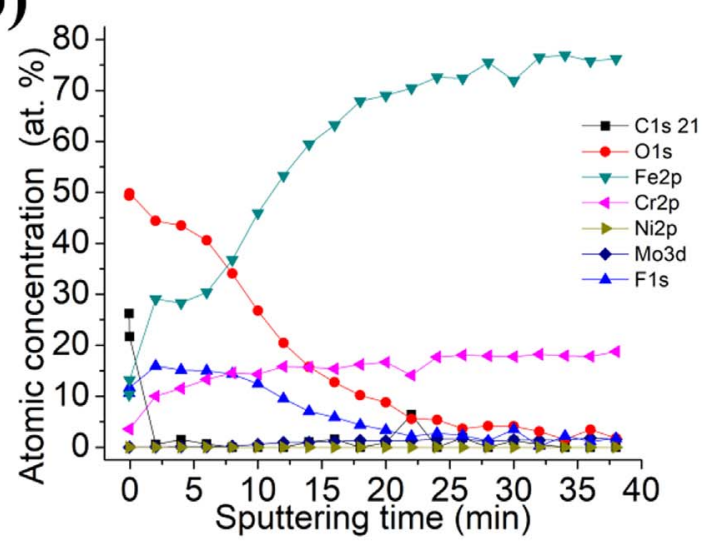

d)

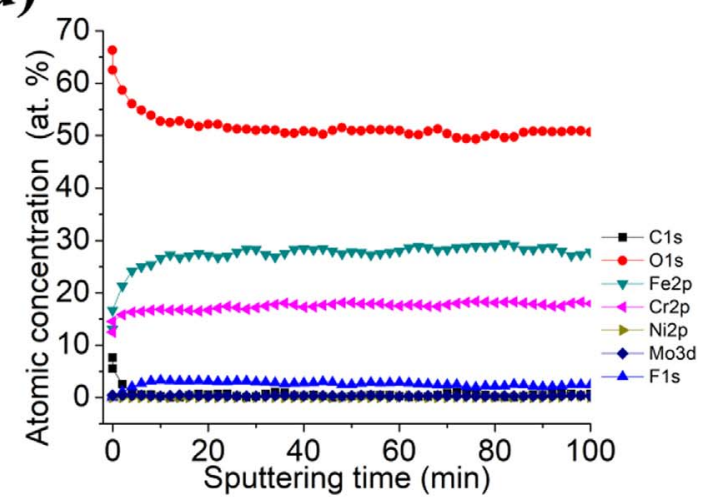

Figure 7. XPS sputter depth profiles of (a) bare AISI 316L, (b) Clean90V, (c) Oxide50V and (d) Oxide90V.

indicating breakdown/repassivation events, especially at the beginning of the measurements. After potentiostatic polarization in chloride containing solutions, pitting corrosion spots were found in places where the porous oxide layer was damaged in a localized manner (see Fig. 9f). This type of corrosion was found in all the anodized samples, where the Oxide50V sample presented more and 
a1)

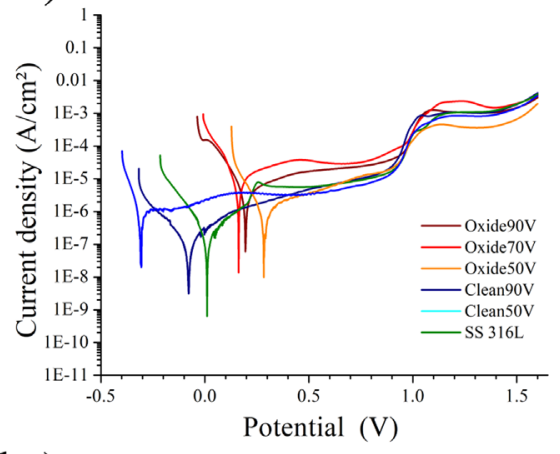

b1)

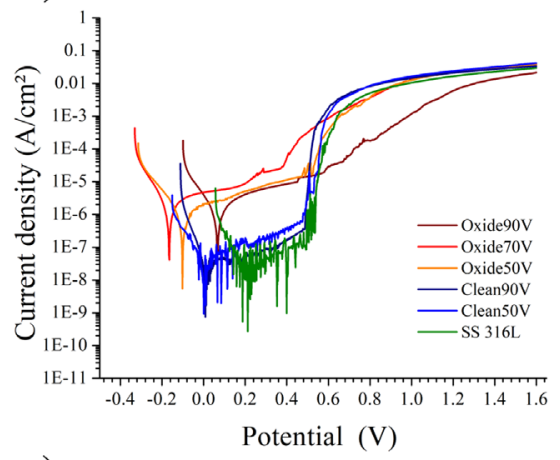

c1)

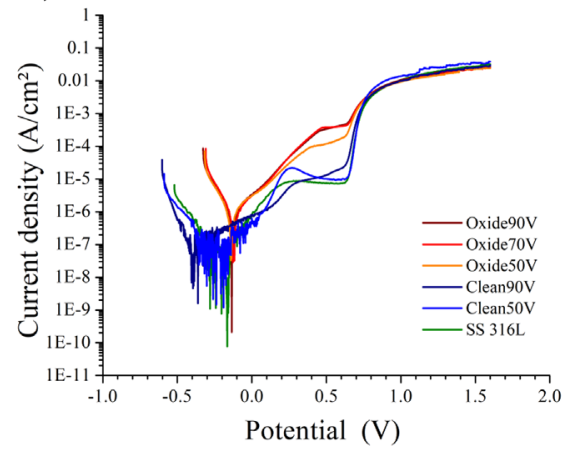

a2)

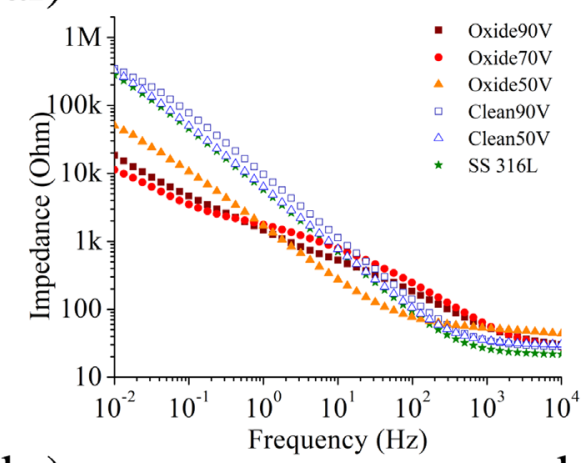

b2)

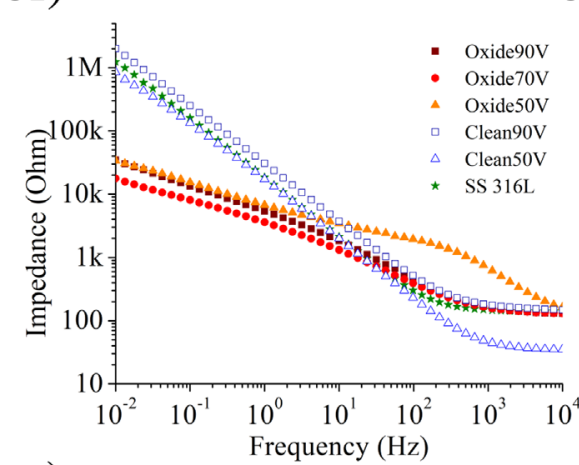

c2)

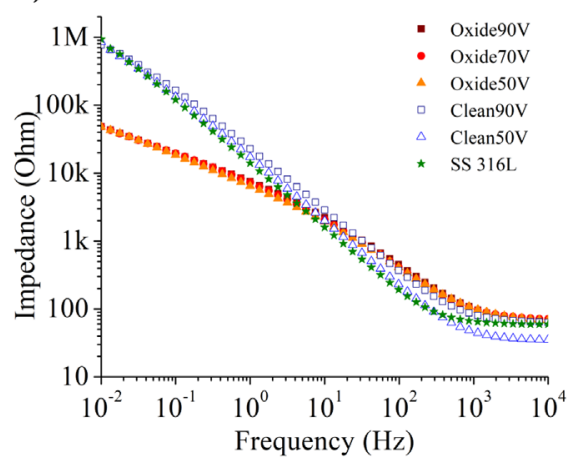

a3)

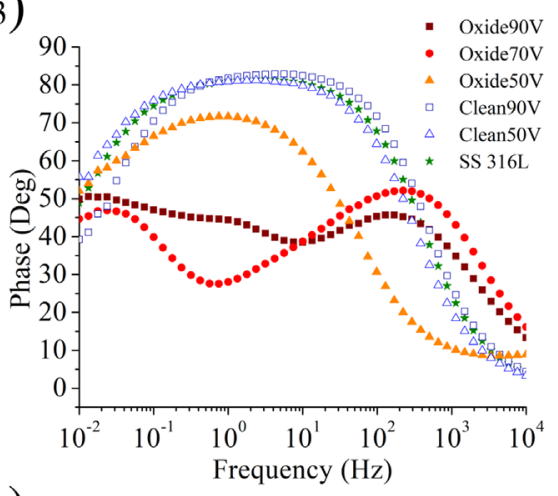

b3)

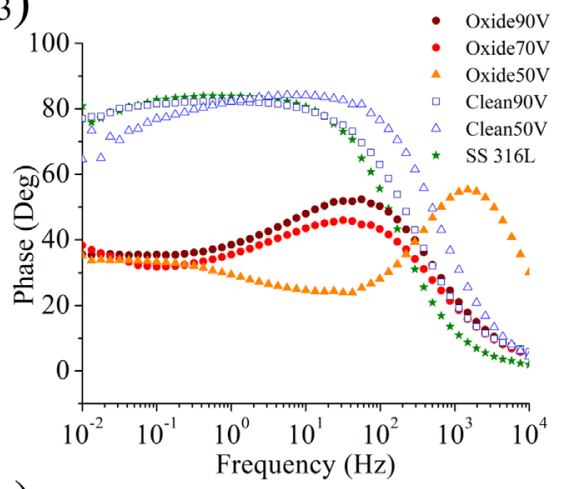

c3)

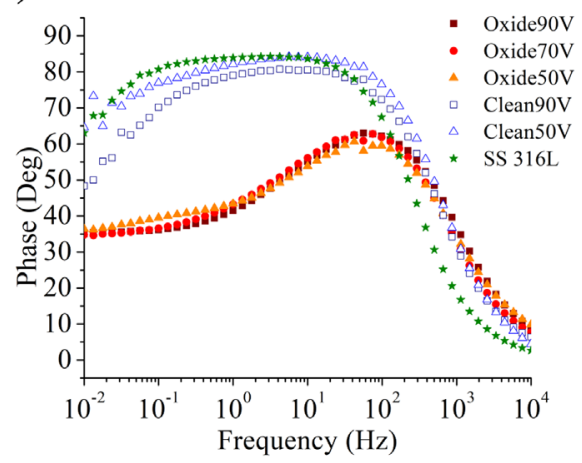

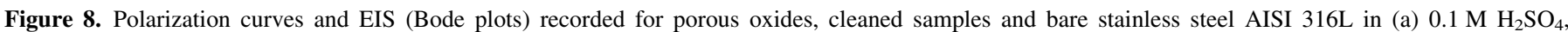
(b) $0.1 \mathrm{M} \mathrm{NaCl}$ and (c) $0.1 \mathrm{M} \mathrm{NaOH}$.

bigger pits, and the sample Oxide90V presented much smaller localized corrosion spots. Thus it can be concluded that thicker anodic oxides produced at higher voltages offer a higher protection against pitting corrosion.

In $0.1 \mathrm{M} \mathrm{NaOH}$, the passive region is limited by early onset of transpassive dissolution (as indicated by the anodic peak corresponding to $\mathrm{Cr}(\mathrm{III})$ oxidation to $\mathrm{Cr}(\mathrm{VI})$ ). Again, the cleaned samples show a very similar behavior to the untreated stainless steel samples, and the samples with the anodic oxide layer show significantly higher current densities.

As shown above, the anodic oxide layers contain fluorine, which could be harmful for the resulting corrosion behavior, as halides can lessen passivity by the onset of pitting corrosion at lower voltages. ${ }^{38}$ However, potentiodynamic polarization in $0.1 \mathrm{M} \mathrm{H}_{2} \mathrm{SO}_{4}$ solution shows that all samples suffer transpassive dissolution in the same potential range as the bare stainless steel (independent of the amount of fluorine detected on the surface, see Table III). Therefore, fluorine that is trapped in the oxide after annealing seems not to impair the passive behavior of the substrate. Nevertheless, it can be pointed out that the fluorine could enhance other corrosion mechanisms which were not evidenced in our experiments.
The potentiodynamic polarization curves in all electrolytes clearly can be divided in two groups, the first group being samples with the anodic oxide layers, and the second one the cleaned and the bare stainless steel substrates. This trend is also visible in the EIS Bode plots (Fig. 10), indicating very clearly how the absolute impedance of the sample with anodic oxide layers is inferior to the bare and cleaned substrates. Furthermore, the phase Bode plot shows how the cleaned substrates present a nearly purely capacitive behavior in a large frequency range, as typical for passive films with a high corrosion resistance. On the other hand, the Bode plots of the anodic oxide layer samples show that the corrosion process has more than one time constant (that may be related to the porous nature of the oxide layers). The only exception is the Oxide50V sample tested in the acidic electrolyte. The fact that the Bode plots clearly can be grouped in the anodic oxide covered samples on one side and the substrates on the other side, suggests a different corrosion mechanism between these two groups. This change in the corrosion mechanism could be due to the different composition of the surface, but also related to the different surface morphology. ${ }^{39}$

A trend that can be seen in all electrolytes when comparing these two sample groups, is that the porous oxides present higher current 

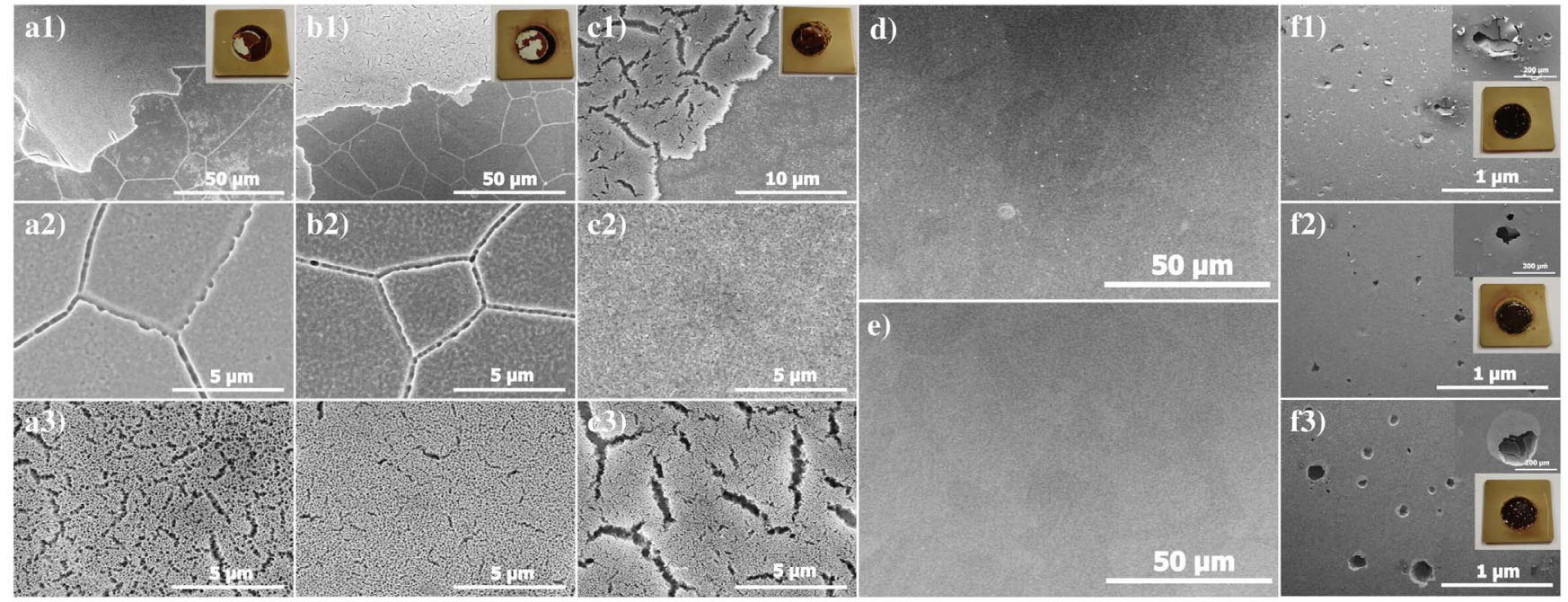

Figure 9. SEM pictures of (a) Oxide90V, (b) Oxide70V, (c) Oxide50V, (d) Clean90V and (e) Clean50V tested in $0.1 \mathrm{M} \mathrm{H}_{2} \mathrm{SO}_{4}$ where it can be seen that the samples in (a) and (b) show clearly intergranular corrosion below the porous oxide while in samples (c)-(e) grain boundaries are not distinguished. Figure (f1) shows sample Oxide90V, f2) Oxide70V and f3) Oxide50V tested in $0.1 \mathrm{M} \mathrm{NaCl}$ where a localized corrosion (pitting) can be seen. Inlet pictures show macroscopic images of the samples were the peeled-off layer and the pitting corrosion spots can be seen.

densities for cathodic and anodic reactions, as well as for lower impedance values. This indicates that the anodic oxide layers contribute to the electrochemical reactions, such as reduction of $\mathrm{Fe}_{2} \mathrm{O}_{3}$ present in the oxide layer during cathodic polarization and oxidation of thus formed lower-valent iron oxide during subsequent anodic polarization; ${ }^{34}$ moreover oxidation of $\mathrm{Cr}_{2} \mathrm{O}_{3}$ into $\mathrm{Cr}(\mathrm{VI})$ species will take place at according potentials. ${ }^{35}$ Due to the large surface area for porous oxides, the nominal current densities are strongly increased due to such reactions. Furthermore, it can also be seen that the cathodic currents of the anodized samples are significantly higher in the acidic and basic electrolyte, while the anodic current is higher in the neutral, chloride-containing solution. The origin of this effect is not currently clear. It may be related to cathodic dissolution of iron oxides on the surface; however the different observations at different $\mathrm{pH}$-values need to be further investigated.

Another clear conclusion that can be made from regrouping the polarization curves in this way, is that the electrochemical behavior confirms that the anodization process does not have a negative effect on the substrate corrosion resistance underneath the formed oxides, as the cleaned samples present a very similar behavior to the bare stainless steel-this is logical considering that there is no significant change in the composition of the metallic substrate beneath the anodic oxide layer.

Interestingly, after performing electrochemical experiments of samples with an oxide layer in the $0.1 \mathrm{M} \mathrm{H}_{2} \mathrm{SO}_{4}$ electrolyte and subsequently gently rinsing the samples with deionized water and drying with a nitrogen stream, the oxide layer peeled off (see Figs. 9a-9c). Given the fact that the only samples that had the oxide detached were the ones tested in the acidic electrolyte and as the oxide that remained on the surface had a porous structure with no signs of deterioration in its nanoporous structure, one possible explanation could be a cathodic dissolution of the thermal iron rich layer ${ }^{40}$ between the porous oxide and the metallic substrate in the acidic electrolyte.

Particularly noteworthy is the fact that in the areas where the oxide peeled off, marked intergranular corrosion was observed. Figures 9a1, 9b1 and 9c1 show an area where the porous oxide layer remained on the surface, and another where the oxide layer detached, revealing clear signs of intergranular corrosion in the metallic substrate. It can also be seen that the remnants of the oxide layer present no cracks that could lead to such localized corrosion pattern. It is noteworthy to point out that the cracks present in the Oxide $50 \mathrm{~V}$ sample (Fig. 9c) were produced during the anodization process, thus were present before the corrosion analysis. It can also be seen that this sample did not present intergranular corrosion. If this type of localized corrosion would originate solely from the anodization process itself, it would also be present on open surfaces of the cleaned samples tested in the acidic electrolyte; however this was not the case (see Figs. 9d-9e). However, intergranular corrosion was also detected in the crevice area between the O-ring sealing and the sample surface for the cleaned samples. Figure 10 shows a diagram of the electrochemical cell together with pictures from the areas where the O-ring was in contact with the Clean90V and Clean50V samples. For both cleaned samples intergranular attack was observed in the crevice area, however for the Clean50V sample in a smaller area; hence intergranular corrosion seems to be intensified when higher voltages are applied in the anodization process. The evidence from these experiments points towards the idea of a crevice-induced intergranular corrosion taking place, i) in the crevice formed between the oxide layer and the metallic substrate when an intermediate iron rich thermal layer is dissolved, and ii) in the crevice between the O-ring and the exposed surfaces of the cleaned samples.

As the stainless steel substrate has a low carbon content and the temperature used during the annealing step is low, it is not likely that the intergranular corrosion in this case originates from chromium rich carbide precipitation at grain boundaries (sensitization). However, even if it is not likely to happen under our conditions, to prove this, a bare polished stainless steel substrate was annealed at $400{ }^{\circ} \mathrm{C}$ for one hour and subsequently corrosion experiments in the acidic electrolyte were performed following the same procedure used for the anodized samples. As expected, this sample did not show any sign of intergranular corrosion even in the crevice region formed by the O-ring (see Fig. S5 in the supplementary information), indicating that the sample did not suffer from sensitization and that the intergranular corrosion observed for oxidized samples is related solely to the anodization process (and not to the annealing of the anodized samples).

The fact that no intergranular corrosion was observed for the bare stainless steel sample and the bare annealed substrate in the O-ring crevice area leads to the conclusion that a combination of an anodization process and presence of a crevice is required for this type of corrosion attack to occur, which is not related to chromiumrich precipitates at grain boundaries, but possibly to a selective de-alloying in the grain boundary region. The increased aggressiveness of the electrolyte due to the crevice formation between the detached oxide layer (before peeling off) and the metallic substrate 
a)

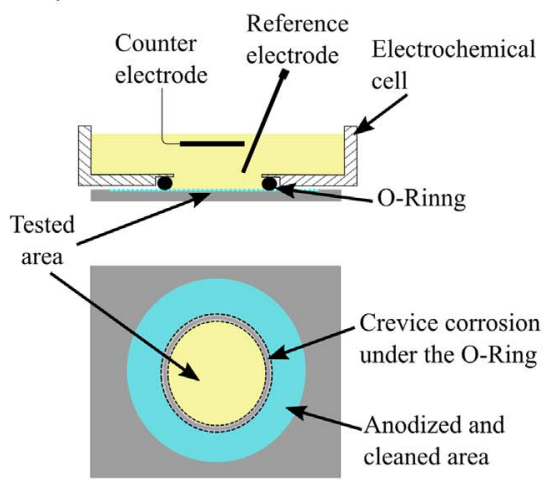

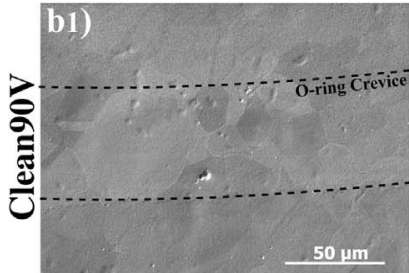

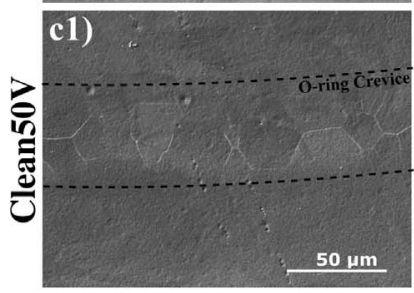

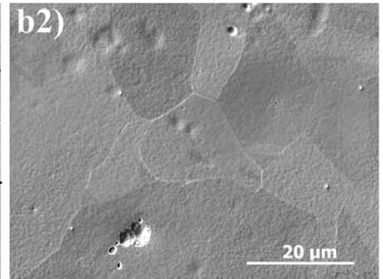
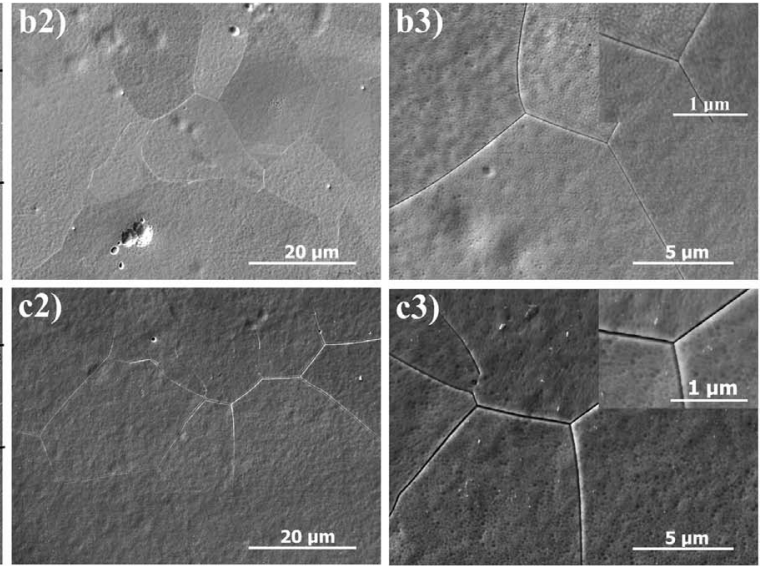

Figure 10. (a) Schematic representation of the electrochemical cell and SEM pictures of samples b1-3) Clean90V and c1-3) Clean50V were it can be seen the location were the O-Ring was in contact with the sample creating a crevice leading to intergranular corrosion. Pictures b1) and c1) show with a dashed lined this region and b2-3) and c2-3) the same location with a higher magnification. Also, it can be seen how the intergranular etching is more intense in the sample anodized at higher voltages.

create the conditions to attack preferentially the grain boundaries with a depleted resistance possibly due to local de-alloying taking place during anodization.

\section{Conclusions and Summary}

DOE for anodization of stainless steel AISI 316L identifies different morphologies that can be achieved with a different combination of parameters. The oxide coverage is directly related to the duration of the anodization, and in a second order to the water content in the ethylene glycol based electrolyte as well as to the interaction between these two parameters. On the other hand, the pore distribution in the oxide is primarily affected by the water content in the electrolyte.

XPS data indicates incorporation of fluorine from the electrolyte in the anodic oxide layers. After annealing, the fluorine concentration decreases but a small amount of remnant fluorine is still detected on the surface. This trapped fluorine however is not deleterious for the corrosion behavior.

The composition of the surface after removing the anodic porous oxide layers is very similar to the bare stainless steel surface. The porous anodic oxide layers are significantly thicker than native airformed passive films on the bare and cleaned stainless steel samples and mainly consist of $\mathrm{Cr}$ and $\mathrm{Fe}$ oxides.

Electrochemical behavior of the bare stainless steel surface, for anodized and annealed samples, and for samples after removal of the anodic oxide layers was compared in acidic, neutral chloridecontaining and alkaline solutions. In all electrolytes, the corrosion behavior of the samples could be grouped on one side by the samples with the oxides grown with different potentials and in another group by the cleaned substrates together with the bare stainless steel. The samples with oxide layers show significantly larger cathodic and anodic current densities than for the bare and cleaned samples, indicating participation of the oxide layers in the electrochemical reactivity (such as reduction of Fe-oxides and oxidation of $\mathrm{Cr}$-oxides in the corresponding potential regimes).

A similarity in the corrosion behavior of the cleaned samples and the bare stainless steel was observed indicating that the anodization process does not significantly impair the corrosion resistance of the underlying substrate. However, after experiments in the acidic electrolyte, the oxide easily peeled-off revealing a marked intergranular corrosion on the metallic substrate. For the cleaned samples, similar intergranular attack after electrochemical experiments in the acidic solution was only observed in the crevice area where the O-ring of the electrochemical cell was in contact with the sample. This crevice-induced intergranular corrosion that takes place between the porous oxide layer and the metallic substrate is possibly due to a cathodic dissolution of a thermal iron rich layer present at the metal/porous oxide interface.

In summary, it can be concluded that stainless steels with anodic porous oxide layers can be used without concerns of corrosion behavior in applications were basic or neutral electrolytes are used, moreover these surfaces also show a good resistance against pitting corrosion in $\mathrm{Cl}-$-containing solutions. However, acidic electrolytes will lead to detachment of the oxide layer and harsh conditions created inside crevices that are formed on the substrate surface can lead to intergranular corrosion of the substrate after such anodization treatments.

\section{Acknowledgments}

Lucia H. Prado thanks the Roberto Rocca Education Program for financial support and Robert Hahn for the advice given for the fabrication of the porous oxides. The author would also thank Sebastian Hagen for the ion milling cross sections and SEM images, Helga Hildebrand for the XPS measurements and Anja Friedrich for SEM images.

\section{ORCID}

Lucia Helena Prado (iD https://orcid.org/0000-0002-6311-5601 Sannakaisa Virtanen (iD https://orcid.org/0000-0002-7179-7593

\section{References}

1. F. Li, L. Zhang, and R. M. Metzger, Chem. Mater., 10, 2470 (1998).

2. S. P. Albu, P. Roy, S. Virtanen, and P. Schmuki, Isr. J. Chem., 50, 453 (2010).

3. A. Ghicov and P. Schmuki, Chem. Commun., 20, 2791 (2009).

4. Y. Konno, S. Yang, E. Tuji, Y. Aoki, P. Skeldon, G. E. Thompson, and H. Habazaki, ECS Trans., 50, 183 (2013).

5. V. Vignal, J. C. Roux, S. Flandrois, and A. Fevrier, Corros. Sci., 42, 1041 (2000)

6. H. Tsuchiya, Mater. Sci. Forum, 783, 2034 (2014).

7. F. Martin, D. Del Frari, J. Cousty, and C. Bataillon, Electrochim. Acta, 54, 3086 (2009)

8. H. Tsuchiya, T. Suzumura, Y. Terada, and S. Fujimoto, Electrochim. Acta, 82, 333 (2012).

9. B. Zhang, H. Ni, R. Chen, W. Zhan, C. Zhang, R. Lei, and Y. Zha, Appl. Surf. Sci., 351, 1161 (2015).

10. S. Fujimoto, K. Tsujino, and T. Shibata, Electrochim. Acta, 47, 543 (2001)

11. J. Doff, P. E. Archibong, G. Jones, E. V. Koroleva, P. Skeldon, and G. E. Thompson, Electrochim. Acta, 56, 3225 (2011)

12. H. H. Farrag, A. A. Abbas, Y. S. Sayed, H. H. Alalawy, B. E. El-Anadouli, A M. Mohammad, and N. K. Allam, ACS Sustainable Chem. Eng., 6, 17352 (2018).

13. K. Kure, Y. Konno, E. Tsuji, P. Skeldon, G. E. Thompson, and H. Habazaki, Electrochem. Commun., 21, 1 (2012).

14. H. Habazaki, K. Shahzad, T. Hiraga, E. Tsuji, and Y. Aoki, ECS Trans., 69, 211 (2015).

15. V. Klimas, V. Pakstas, I. Vrublevsky, K. Chernyakova, and A. Jagminas, J. Phys Chem. C, 117, 20730 (2013).

16. Y. Wang, G. Li, K. Wang, and X. Chen, Appl. Surf. Sci., 505, 144497 (2020). 
17. D. E. Williams, M. R. Kilburn, J. Cliff, and G. I. Waterhouse, Corros. Sci., 52, 3702 (2010).

18. L. P. Domínguez-Jaimes, M. A. Arenas Vara, E. I. Cedillo-González, J. J. Ruiz Valdés, J. J. De Damborenea, A. Conde Del Campo, F. J. Rodríguez-Varela, I. L. Alonso-Lemus, and J. M. Hernández-López, Coatings, 9, 706 (2019).

19. J. Lee, S. Wooh, and C.-H. Choi, J. Colloid Interface Sci., 558, 301 (2020).

20. M. Sieber, I. Althöfer, D. Höhlich, I. Scharf, D. Böttger, S. Böttger, E. S. Böttger, and T. Lampke, IOP Conf. Ser.: Mater. Sci. Eng., 118, 12038 (2016).

21. J. L. Rosa, A. Robin, R. Z. Nakazato, M. B. Ribeiro, M. P. Piassa, and M. B. Silva, Surf. Eng., 30, 115 (2014).

22. A. Robin, M. Bernardes de Almeida Ribeiro, J. Luiz Rosa, R. Zenhei Nakazato, and M. Borges Silva, J. Surface Eng. Mater. Adv. Technol., 4, 123 (2014).

23. C. A. Schneider, W. S. Rasband, and K. W. Eliceiri, Nat. Methods, 9, 671 (2012)

24. RStudio Team, RStudio: Integrated Development Environment for $R$ (RStudio PBC, Boston) (2020), http://www.rstudio.com/.

25. D. A. Pinder and M. E. Witherick, Geography, 57, 277 (1972).

26. B. J. L. Berry and D. F. Marble, Spatial Analysis A reader in statistical geography (Prentice-Hall , Englewood Cliffs, NJ )2, 159 (1968).

27. P. A. Rogerson,, Statistical Methods for Geography: A Student's Guide (Sage Publications Limited, London) 8, 161 (2019)

28. M. F. Acevedo, Data Analysis and Statistics for Geography, Environmental Science, and Engineering (Crc Press, London) 8, 264 (2012).
29. Y. Mao, Nearest Neighbor Distances Calculation with Image (2020), https://icme hpc.msstate.edu/mediawiki/index.php/Nearest_Neighbor_Distances_Calculation_ with_ImageJ.html.

30. S. Özkan, A. Mazare, and P. Schmuki, Electrochem. Commun., 65, 18 (2016).

31. X. M. Li, D. Reinhoudt, and M. Crego-Calama, Chem. Soc. Rev., 36, 1350 (2007).

32. A. T. Abdulhussein, G. K. Kannarpady, A. B. Wright, A. Ghosh, and A. S. Biris, Appl. Surf. Sci., 384, 311 (2016).

33. P. Schmuki, S. Virtanen, A. J. Davenport, and C. M. Vitus, J. Electrochem. Soc. 143, 3997 (1996)

34. C. O. Olsson and D. Landolt, Electrochim. Acta, 48, 1093 (2003).

35. M. C. Biesinger, B. P. Payne, A. P. Grosvenor, L. W. Lau, A. R. Gerson, and R. S C. Smart, Appl. Surf. Sci., 257, 2717 (2011).

36. NIST X-ray Photoelectron Spectroscopy Database, NIST Standard Reference Database Number 20 (National Institute of Standards and Technology, Gaithersburg MD) (2000).

37. V. Maurice, H. Peng, L. H. Klein, A. Seyeux, S. Zanna, and P. Marcus, Faraday Discuss., 180, 151 (2015).

38. R. C. Newman, Corrosion, 57, 1030 (2001).

39. K. Jüttner, Electrochim. Acta, 35, 1501 (1990).

40. R. Sánchez-Tovar, R. Leiva-García, and J. García-Antón,, Thin Solid Films, 576, 1 (2015). 